\title{
CALCULATION OF THE VERTICAL DISTRIBUTION OF WATER TEMPERATURE IN THE BLACK SEA BY SATELLITE DATA
}

\author{
Andrii SRYBERKO ${ }^{I}$
}

DOI: 10.21163/GT_2019.142.09

\begin{abstract}
:
The studies on calculation of vertical distribution of water temperature in the Black Sea by satellite data are described. The research was carried out in the active layer of the deep part of the Black Sea at depths of $0-50$ meters. The initial data of the actual water temperature values were station data or measurement from the ship data (OSD - Ocean Station data), data measured with the help of floats (PFL - Profiling float data) and satellite data of the sea surface temperature. Calculations were based on the definition of statistical dependencies between the values of water temperature at the neighboring levels of vertical temperature distribution in the Black Sea by OSD \& PFL data of water temperature and the development of regression equations. Calculations showed statistically significant results in spring-autumn period. Correlation coefficients between the values of the water temperature on the neighboring levels in the Black Sea amounted to $0.88-0.99$. To increase the accuracy of results the equations for the calculation of adjustments for the temperature of the water at depths: 10, 20, 25 and 50 meters were developed. Standard calculation errors of the vertical distribution of water temperature amounted to $2{ }^{\circ} \mathrm{C}$ in the Black Sea in 2017 year.
\end{abstract}

Key-words: Black Sea, water temperature calculation, correlation coefficient, statistical dependence, regression equation, satellite data.

\section{INTRODUCTION}

Water temperature is the most regularly measured parameter by comparison with other hydrological characteristics and can be used as an indicator for hydrophysical, hydrochemical, hydrobiological processes of the World Ocean.

Implementations of various contemporary ocean research programs in the last decade have generated considerable progress toward understanding the Black Sea's basic physical and biogeochemical processes. Physical and biogeochemical data accumulated from these studies were able to resolve many features of the Black Sea circulation and ecosystem structure. The description and understanding of basin scale dynamical features have reached maturity. Modelling and data assimilation tools have been developed and implemented but they still require further calibration and validation exercises by availability of new data sets (Oguz et al., 2004).

Primarily study on verification and calibration data are based on the set of satellite measurements and data from the stations or it can be based on the sea surface temperature data measured from the ship (Andrianova et al., 2004; Kara et al., 2008; Dufois et al., 2012).

\footnotetext{
${ }^{1}$ Hydroacoustics Branch of Institute of Geophysics of National Academy of Sciences of Ukraine, 3 Preobrazhenska st., Odesa, 65082, Ukraine, sriberko@gmail.com
} 
Research of water temperature based on satellite information in the Black Sea aims to study sea surface temperature variability (Manev et al., 2005; Shapiro, Aleynik \& Mee, 2010). Despite many researches the identification and analysis of trends and temperature anomalies in the long-term variability of the thermohaline characteristics are under the major focus. But the possibility of creating they're of vertical distribution based on satellite data is practically unexplored.

Indirect definitions of the vertical distribution of water temperature, i.e. through the development of various methods for the calculation of the distribution of water temperature on the vertical are used to date (Andrianova et al., 2015).

Study of vertical distribution of water temperature in the Black Sea was carried out in the deep-water part sea at standard levels $(0,10,20,25,30,50$ meters $)$ in spring - autumn period. This area of research is represented by the highest number of measurements and is included in the Main Black Sea current zone.

\section{MATERIAL AND METHODS}

Calculations of the vertical distribution of water temperature in the Black Sea are founded on the "Method of calculation of the vertical distribution of water temperature in the Black Sea based on satellite information" (hereinafter referred to as the Method) created by us in 2015 year (Andrianova et al., 2015).

In undertaking this work the developed Method (Andrianova et al., 2015) was significantly completed with new equations, criteria for calculations, corrections for the temperature of the water, which significantly improve the accuracy of the calculations of the vertical distribution of water temperature. Complex calculations of linear and exponential regression equations were included in the last Method version compare to Method of the 2015 year where the calculations were performed only on the equations of exponential regression.

\subsection{Initial data}

Initial data were used to determine the statistical dependencies between values of water temperature on the neighboring levels 10, 20, 25, 30, 50 meters in the Black Sea and to create the regression equations. Those initial data were the actual water temperature data from the stations or measured data from the ship (OSD - Ocean Station data) from 1890 to 2005 years and data measured using floats (PFL - Profiling float data) from 2005 to 2017 years (NOAA, 2019).

Due to the small number of OSD and PFL water temperature data on the level 0 meters a climatic data of satellite measurements of the Black Sea surface temperature $\left(T_{\text {clim }}\right)$ with step $4 \mathrm{~km}$ to latitude and longitude measured companion NASA (Terra MODIS) (NASA's OceanColor Web, 2019) from 2000 on the 2017 years were used as initial data.

The initial satellite data were the daily data on satellite measurements of the Black Sea water surface temperature with $4 \mathrm{~km}$ step on latitude and longitude, measured companion NASA (Terra MODIS) (NASA's OceanColor Web, 2019) were used to calculate the vertical distribution of water temperature in the Black Sea.

Analysis and comparative estimation of calculations of vertical distribution of water temperature by satellite data was carried out between the values calculated on the regression equations and PFL data (Profiling float data) of water temperature on standard levels in 2017 year (NOAA, 2019). 


\subsection{Method of calculation}

Calculations of vertical distribution of water temperature in the Black Sea were carried out in three main stages.

The first stage - the finding of statistical dependences between the values of water temperature at the neighboring levels in the Black Sea according to the data of water temperature and the creation of regression equations.

The second stage - setting the criterion for calculating the vertical distribution of water temperature $( \pm \Delta T)$.

The third stage - calculation of water temperature corrections at depths of 10, 20, 25, 50 meters.

The first stage of the calculation. To development the regression equations the average by 72 squares (Fig. 1) in the size of 40' to 60', months and standard levels perennial (for the period from 1890 to 2017) OSD and PFL data of the water temperature in the Black Sea were used.

The data were selected for spring - autumn period because there are small amount of data available during the cold period of the year.

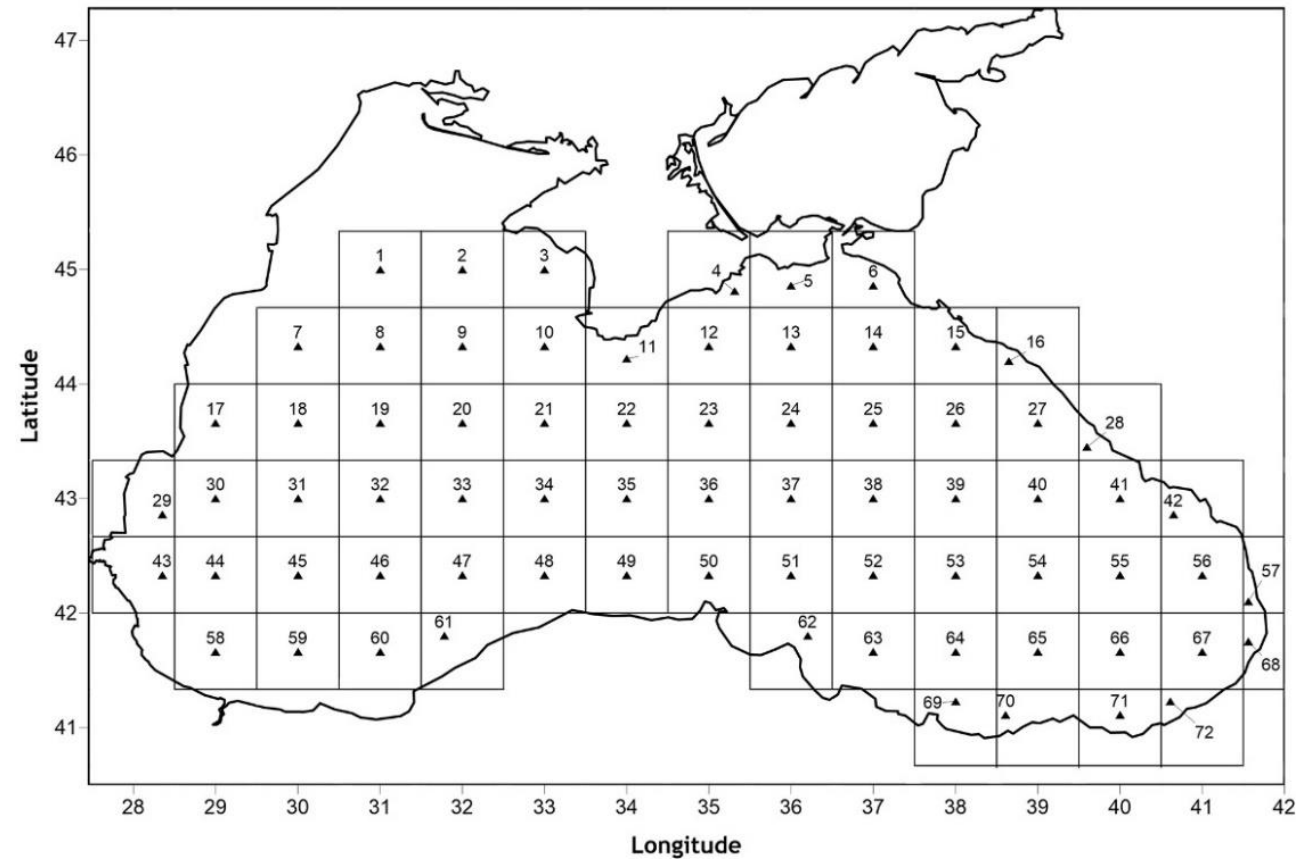

Fig. 1. Location of squares (square size $40^{\prime}$ to $60^{\prime}$ ) for calculating regression equations in the Black Sea.

Equation of exponential and linear regression was calculated in each square (Fig. 1) (Kobzar, 2006; Eliseeva, 2007; Andrianova et al., 2015; Hogg, Tanis \& Zimmerman, 2015; Ahn, 2018) for a particular month of the year

$$
y=a e^{b x},
$$

and 


$$
y=a x+b,
$$

where $\mathrm{a}$ and $\mathrm{b}$ are regression coefficients; $\mathrm{y}$ - water temperature at the studied level; $\mathrm{x}$ water temperature on the overlying level.

The second stage of the calculation. In (Glagoleva \& Skriptunova, 1979) states that the change of the vertical profile of water temperature is obey the exponential distribution law. Our researches show that at large deviations of values of sea surface temperature from climatic values $\left(T_{\text {clim }}\right)$ of water temperature the linear dependence between values of water temperature on neighboring levels prevails.

The criterion $( \pm \Delta T)$ serves as a factor determining the method of calculating the vertical distribution of water temperature by the equations of exponential or linear regression. The role of the criterion $( \pm \Delta T)$ is to set the boundary conditions for calculating the water temperature according to the exponential regression equations or linear regression equations.

If the value of the sea surface temperature $\left(T_{0}\right)$ is in the interval $\left[T_{\text {clim }}-\Delta T<T_{0}<T_{\text {clim }}+\Delta T\right]$, the vertical distribution of water temperature is calculated by exponential regression equations. If $T_{0}$ is not included in that interval, the linear regression equation is used.

The criterion value $( \pm \Delta T)$ for the calculation of the vertical distribution of water temperature is determined experimentally and individually for specific water areas of the World Ocean depending on its hydrological conditions.

The third stage of the calculation. Calculation of water temperature corrections (hereinafter referred to as the correction) at depths of 20,25, 50 meters were conducted by finding statistical dependencies between values of water temperature on the neighboring levels and building linear equations of regression

$$
\delta y_{z}=a x_{k}+b
$$

where $\delta y_{z}$-the water temperature at depth $z$ meters; $x_{k}$ - the water temperature at a depth $k$ meters; $a$ and $b$ coefficients of the regression equation.

For a correction on 20 meters the dependence between the values of water temperature on the levels $25-20$ meters, for corrections on 25 and 50 meters - on the levels of $30-25$ meters and $30-50$ meters respectively was determined.

The calculation of the correction at a depth of 10 meters is more complex than for 20 , 25, 50 meters. The calculations have been carried out by the method of the analytical presentation of the distribution of surface water temperature as functions of the coordinates. Satellite data of sea surface temperature were decomposed into the ranks on algebraic polynomials - the Chebyshev polynomials (Kobzar, 2006; Gil, Segura \& Temme, 2007). In marine forecasts this method was used for the first time by N. A. Belinsky, M. G. Glagoleva (Kudryavaya, Seryakov \& Skriptunova, 1974).

Using decomposition by Chebyshev polynomials the water temperature field is represented as a sum of elementary fields each of which describes the individual traits of the real distribution. Decomposition of a function of two variables in a series on Chebyshev polynomials is 


$$
T(x, y)=A_{00} \varphi_{0}(x) \psi_{0}(y)+A_{10} \varphi_{1}(x) \psi_{0}(y)+\cdots+A_{i j} \varphi_{i}(x) \psi_{j}(y),
$$

where $\varphi_{i}, \psi_{j}$ - Chebyshev polynomials representing the parabola $i, j-\operatorname{order}(i=1,2$, $\ldots, M ; j=1,2, \ldots, N), A_{i j}$ - coefficients of decomposition.

The values of the coefficients of the decomposition are calculated according to the equation:

$$
A_{i j}=\frac{\sum_{m=1}^{k} \sum_{n=1}^{l} T\left(x_{m}, y_{n}\right) \varphi_{i}\left(x_{m}\right) \psi_{j}\left(y_{n}\right)}{\sum_{m=1}^{k} \varphi_{i}^{2}\left(x_{m}\right) \sum_{n=1}^{l} \psi_{j}^{2}\left(y_{n}\right)}
$$

where $k$ - number of nodes, which is set to feature in the direction of axis $x, l-$ in the direction of axis $y$.

The function field $T\left(x_{m}, y_{n}\right)$ is represented as a matrix

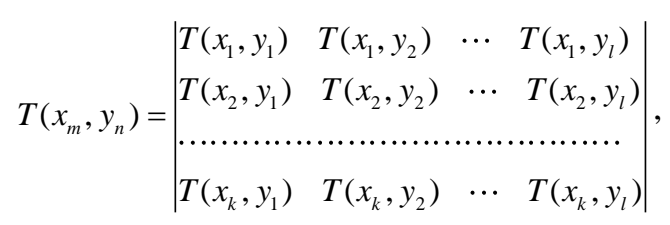

The absolute values of the decomposition coefficients $A_{i j}$ show the specific weight of this elementary field in the source field, which is represented as a series.

To simplify calculations it is convenient to use the method proposed by B.H. Rybak (Kudryavaya, Seryakov \& Skriptunova, 1974).

If

$$
Z=F(T)
$$

and the distribution of $T$ is represented analytically Chebyshev polynomials, i.e.

$$
T=f\left(A_{00} A_{10} \cdots A_{i j}\right)
$$

the regression equation for $Z$ will be written as

$$
Z=a_{0}+a_{1} A_{00}+a_{2} A_{10}+a_{3} A_{01}+\cdots+a_{r} A_{i j}
$$

where $a_{0}, a_{1}, a_{r}$ - numeric coefficients of the regression equation; $A_{00}, A_{10}, A_{01}, \ldots$, $A_{i j}$ - coefficients of decomposition in a series on Chebyshev polynomials element $\mathrm{T}$ from which distribution the function $Z$ depends.

Therefore, to calculate the $\mathrm{Z}$ function the coefficients $A_{i j}$ must be calculated first by the equation (5) and then substituted in equation (9).

The sequence of calculation of temperature corrections as follows: calculate the correction at 25 meters first, then to 20 and 10 meters, and at 50 meters in the autumn. 


\subsection{Statistical characteristics for estimating calculations}

The measure of statistical dependence between the values of the water temperature was: when linear dependence - linear coefficient of correlation $r(-1 \leq r \leq 1)$, the coefficient of multiple correlation $R(0 \leq R \leq 1)$, with nonlinear dependence - correlation index $I(0 \leq I \leq 1)$ (Draper and Smith, 1998; Kobzar, 2006; Eliseeva et al., 2007; Hogg, Tanis \& Zimmerman, 2015).

To assess the significance of the correlation index (I), linearization was applied to the exponential equations (1). If we take the (natural) logarithm of both sides of equation (1), we get

$$
\operatorname{Ln}(y)=\operatorname{Ln}(a)+b x
$$

if we define $y^{\prime}=\operatorname{Ln}(y)$ and $a^{\prime}=\operatorname{Ln}(a)$. We get: $y^{\prime}=a^{\prime}+b x$. This is the equation of a straight line (linear). Then, the measure of statistical dependence will be described by the correlation coefficient $r^{\prime}$. In our case, the value of the correlation index $(I)$ is equal to the value of the correlation coefficient $r^{\prime}\left(I=r^{\prime}\right)$.

Checking the significance of $r, R, r^{\prime}$ was carried out by comparing the correlation coefficients with the critical value of the correlation coefficients $r(\alpha)$ (for pair correlation) and $R(\alpha)$ (for multiple correlation) at a significance level $\alpha=0.05$ (or confidence coefficient $(1-\alpha)=0.95)$.

The critical value of the correlation coefficients $r(\alpha)$ can be calculated by the equation:

$$
r(0.05)=\sqrt{\frac{t_{0.025}^{2}}{n-2+t_{0.025}^{2}}},
$$

where $t_{0.025}$ - the critical values of Student's $t$ distribution at significance level $\alpha=$ 0.025 (or confidence coefficient $(1-\alpha)=0.975), n$ - the number of members of the series.

For multiple correlation:

$$
R(0.05)=\sqrt{\frac{(k-1) F_{0.05}\left(f_{1}, f_{2}\right)}{n-k+(k-1) F_{0.05}\left(f_{1}, f_{2}\right)}},
$$

where $F_{0.05}$ - the critical value for an $F$ distribution with $f_{1}$ and $f_{2}$ degrees of freedom at significance level $\alpha=0.05$ (or confidence coefficient $(1-\alpha)=0.95$ ), $n$ - the number of members of the series, $k$ is the number of variables in the regression equation (Kobzar, 2006).

Also, $r(\alpha)$ and $R(\alpha)$ can be determined from the tables (Kobzar, 2006; Hogg, Tanis \& Zimmerman, 2015; Ahn, 2018).

If $r$ (or $R) \geq r(\alpha)$ (or $R(\alpha)$, respectively), then the corresponding correlation is considered significant (Kobzar, 2006).

Another criterion of significance $r, R, r^{\prime}$ was the ratio $r / E_{r}$. To assess the correlation values the values of probability errors $E_{r}, E_{R}, E_{r^{\prime}}$ of correlation coefficients were calculated (Kudryavaya, Seryakov \& Skriptunova, 1974), according to the type of dependency: 


$$
E_{k}=0.67 \frac{1-r^{2}}{\sqrt{n}},
$$

where $k$ - the index of the correlation's values $\left(r, r^{\prime}, R\right), r$ - the correlation coefficient $\left(r, r^{\prime}, R\right), n$ - the number of members of the series.

At reliable dependencies the correlation coefficient $(r)$ in 6 to 10 times greater than its the probable error $E_{r}$ (Kudryavaya, Seryakov \& Skriptunova, 1974).

The assessment of the significance and reliability of linear regression equations was carried out by the critical value for an $F$ distribution with $f_{1}$ and $f_{2}$ degrees of freedom $F_{\alpha}\left(f_{1}, f_{1}\right)$ at significance level $\alpha=0.05$ (or confidence coefficient $(1-\alpha)=0.95$ ). If the calculated value of $F>F_{\alpha}\left(f_{1}, f_{1}\right)$ (critical), then the statistical regression equation reliability is recognized as significant and reliable (Kobzar, 2006; Eliseeva et al., 2007).

Also, the estimation of the accuracy of the calculations is determined by the efficiency of the method. The ratio $S / \sigma_{T}$ allows determining the reliability and efficiency of the calculation method simultaneously. $S$ is a mean square error of the correlation (standard error) and $\sigma_{T}$ is the standard deviation of the actual values (standard deviation) (Kudryavaya, Seryakov \& Skriptunova, 1974; Abuzyarov et al., 1988). The values of $S$ and $\sigma_{T}$ can be calculated by known formulas (Kudryavaya, Seryakov \& Skriptunova, 1974; Abuzyarov et al., 1988; Deep, 2006; Kobzar, 2006; Hogg, Tanis \& Zimmerman, 2015; Ahn, 2018).

The ratio $S / \sigma_{T}$ is smaller, the method is more reliable. For a functional dependency of ratio $S / \sigma_{T}=0$, and at $S / \sigma_{T}=1$ variation of the function does not depend on variations of the argument. Consequently the relationship between variables is absent (Kudryavaya, Seryakov \& Skriptunova, 1974; Abuzyarov et al., 1988). For our calculations of the vertical distribution of water temperature the permissible error is: $S / \sigma_{T} \leq 0.57$ at $n \leq 15$ and $S / \sigma_{T} \leq 0.67$ at $n>25$.

\section{RESULTS}

\subsection{Development of regression equations and determination of criteria's for calculation}

In each square (Fig. 1) the equations exponential and linear regression (1) and (2) were built for each month in the period May - October. The total number of equations exponential regressions amounted to 432 and linear regression equations - 432 respectively.

Correlation coefficients $\mathrm{r}$ and $r^{\prime}(I)$ were within $0.88-0.99$ at the developing regression equations stage. They did not exceed the critical value $r(0.05)=0.878$ (Kobzar, 2006; Hogg, Tanis \& Zimmerman, 2015).

Probabilistic errors $E_{r}$ and $E_{r^{\prime}}$ of the correlation coefficients $r, r^{\prime}$ were calculated according to the equation (12). Errors do not exceed 0.07 during the period May - October. The minimum values of the relations $r / E_{r}$ and $r / E_{r^{\prime}}$ is 13 . That means a correlation is reliable between the averaged values of water temperature in all squares of the Black Sea (Fig. 1) in the period May - October. 
The calculated values of $F$ were within $10.36-1136.43$ and greater than the critical value $F_{0.05}=10.13$. The values of the criterion $\left(S / \sigma_{T}\right)$ were $0.06-0.55$, which is less than the critical value 0.57 . This means that all the developed regression equations are effective, reliable and significant.

To visualize we shall give an example of calculation of vertical temperature distribution by satellite data at three stations and compare the obtained results with PFL data measured on 30.05.2017, 27.06.2017 and on 10.09.2017 respectively. Coordinates of the first station -Longitude: $29,038^{\circ}$, Latitude: $42,138^{\circ}$, the second station - Longitude: $36,294^{\circ}$, Latitude: $42,172^{\circ}$ and the third - Longitude: $37,990^{\circ}$, Latitude: $43,480^{\circ}$.

Considering the Fig. 1 we define that the stations fall into the squares 44, 51 and 26 respectively.

The criterion $( \pm \Delta T)$ was used as determining factor in the calculations of the vertical distribution of water temperature on equations, exponential or linear regression.

Studies have shown ( $>1000$ numerical experiments) that when the deviation of the sea surface temperatures from climatic values of water temperature $\left(T_{\text {clim }}\right)$ in the Black Sea is $\pm 2^{\circ} \mathrm{C}$ a linear relationship between water temperature values is dominated on the neighbouring levels.

Thus, if the value of the sea surface temperature $\left(T_{0}\right)$ is in the interval $\left[T_{\text {clim }}-\Delta T<T_{0}<T_{\text {clim }}+\Delta T\right]$, the vertical distribution of water temperature is calculated by, exponential regression equations (1). If they are not included in this interval, the equations of linear regression (2) are used.

For our example the calculation intervals and the predominant type of statistical dependency are shown in Table 1.

Table 1.

Intervals for the determination of the predominant types of statistical dependence.

\begin{tabular}{|c|c|c|c|c|c|c|}
\hline $\begin{array}{c}\text { Number } \\
\text { Station }\end{array}$ & $\begin{array}{c}\text { Number } \\
\text { square }\end{array}$ & Month & $\mathbf{T}_{\mathbf{0}}\left[{ }^{\circ} \mathbf{C}\right]$ & $\mathrm{T}_{\text {clim }}\left[{ }^{\circ} \mathbf{C}\right]$ & Interval $\left[{ }^{\circ} \mathbf{C}\right]$ & $\begin{array}{c}\text { Statistical } \\
\text { dependence }\end{array}$ \\
\hline 1 & 44 & 5 & 17.770 & 15.63 & {$[13.63-17.63]$} & Linear \\
\hline 2 & 51 & 6 & 22.145 & 20.98 & {$[18.98-22.98]$} & Exponential \\
\hline 3 & 26 & 9 & 24.500 & 23.37 & {$[21.37-25.37]$} & Exponential \\
\hline
\end{tabular}

Table 1 shows that at the station 1 the calculation of the vertical distribution of water temperature needs to be carried out on a linear regression equation and at stations 2 and 3 by the equations of exponential regression.

Considering the values of the criterion $( \pm \Delta T)$ and intervals (Table 1) the vertical distribution of water temperature at station 1 is calculated by linear regression equation, and at stations 2 and 3 - on exponential regression equations.

The built regression equations by formulas (1) and (2) for our example, and the corresponding of the standard errors $(S)$ of calculation are presented in Table 2.

Table 2.

The regression equation, standard errors $(S)$ of calculations of the vertical temperature distribution.

\begin{tabular}{|c|c|c|c|c|}
\hline $\begin{array}{c}\text { Number } \\
\text { station }\end{array}$ & $\begin{array}{c}\text { Number } \\
\text { square }\end{array}$ & Month & $\begin{array}{c}\text { The regression } \\
\text { equation }\end{array}$ & $\boldsymbol{S}$ \\
\hline 1 & 44 & 5 & $y=0.9207 x-0.6741$ & 1.41 \\
\hline 2 & 51 & 6 & $y=4.6081 e^{0.0628 x}$ & 2.27 \\
\hline 3 & 26 & 9 & $y=5.1155 e^{0.0531 x}$ & 2.37 \\
\hline
\end{tabular}


The vertical distribution of water temperature is calculated by the regression equations (Table 2) from the surface to a depth of 50 meters. The water temperature values on the surface are satellite data of sea surface temperature.

The results of calculations on regression equations (Table 2) are presented in Fig. 2.

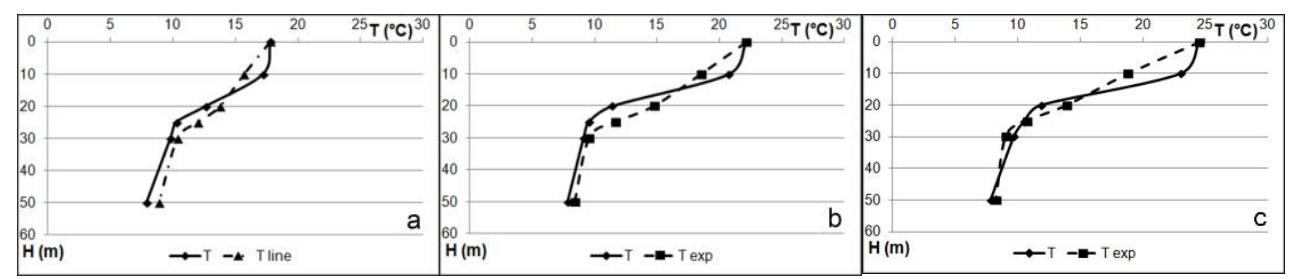

Fig. 2. The graphs of the vertical distribution of water temperature at stations 1 (a), 2 (b) and 3 (c) built on the PFL data $(T)$ and calculated values by the equations of exponential $\left(T_{\exp }\right)$ and linear $\left(T_{\text {line }}\right)$ regressions (Table 2).

Fig. 2 shows that PFL data and the calculated value of water temperature on standard levels well consistent. Weak match between PFL data and calculated values is observed only in the thermocline zone at a large gradient of temperatures. It is confirmed by the results of research conducted by us previously (Andrianova et al., 2015).

\subsection{Calculation of water temperature corrections at depths of 10, 20, 25, 50 meters}

To improve the results of calculation of the vertical distribution of water temperature based on the satellite data, regression equations were developed to calculate the water temperature corrections at depths of 10,20,25 and 50 meters.

Research has shown that water temperature corrections must be entered depending on the time of the year. So, for the spring - summer period the correction at depths of 10, 20, 25 meters should be introduced. For autumn correction should be introduced at depths of $10,20,25$ and 50 meters.

The built linear regression equations by equation (3) for corrections at a depth of 20 , 25, 50 meters and the relevant criteria for accuracy and effectiveness of the regression equations are presented in Table 3.

Table 3.

The regression equations for corrections at a depth of 20, 25, 50 meters, statistical characteristics.

\begin{tabular}{|c|c|c|c|c|c|c|c|c|}
\hline $\begin{array}{c}\text { Season } \\
\text { of the } \\
\text { year }\end{array}$ & $\begin{array}{c}\text { Depth } \\
(\mathbf{m})\end{array}$ & $\begin{array}{c}\text { The regression } \\
\text { equation }\end{array}$ & $\boldsymbol{r}$ & $\boldsymbol{r ( \mathbf { 0 . 0 5 } )}$ & $\boldsymbol{r} / \boldsymbol{E}_{\boldsymbol{r}}$ & $\boldsymbol{F}$ & $\boldsymbol{F}_{0.05}$ & $\boldsymbol{S} / \boldsymbol{\sigma}_{\boldsymbol{T}}$ \\
\hline \multirow{2}{*}{ Spring } & 20 & $y_{20}=1.08 x_{25}+0.323$ & 0.93 & 0.03 & 620 & 25187 & 3.84 & 0.44 \\
\cline { 2 - 9 } & 25 & $y_{25}=0.98 x_{30}+0.999$ & 0.91 & 0.03 & 506 & 19301 & 3.84 & 0.46 \\
\hline \multirow{2}{*}{ Summer } & 20 & $y_{20}=1.02 x_{25}+1.756$ & 0.97 & 0.02 & 2425 & 142229 & 3.84 & 0.27 \\
\cline { 2 - 9 } & 25 & $y_{25}=1.08 x_{30}+0.714$ & 0.98 & 0.02 & 3267 & 208227 & 3.84 & 0.24 \\
\hline \multirow{3}{*}{ Autumn } & 20 & $y_{20}=0.85 x_{25}+3.933$ & 0.91 & 0.03 & 535 & 21691 & 3.84 & 0.38 \\
\cline { 2 - 9 } & 25 & $y_{25}=0.90 x_{30}+2.945$ & 0.94 & 0.03 & 783 & 33459 & 3.84 & 0.32 \\
\cline { 2 - 9 } & 50 & $y_{50}=0.33 x_{30}+4.385$ & 0.57 & 0.08 & 75 & 293 & 3.85 & 0.43 \\
\hline
\end{tabular}


As can be seen from Table 3, that all calculated statistical characteristics do not exceed critical values. This means a correlation between values of water temperature throughout the Black Sea in spring - autumn period is reliable and indicates the effectiveness of the developed regression equations.

The calculation of the corrections at a depth of 10 meters was carried out by method of the statistical dependencies between satellite values of sea surface temperature and values of PFL data of water temperature at a depth of 10 and 20 meters. Further equations of multiple regression were built.

Satellite data of water temperature on the surface were presented in the form of water temperature fields and formed a matrix ( 5 on 5) with step 5 to the latitude at 5 in longitude. Water temperature fields were set by 25 points through $4 \mathrm{~km}$ in latitude and $4 \mathrm{~km}$ in longitude. Fig. 3 shows an example of the location of the satellite data values of the water temperature to calculate the correction at a depth of 10 meters.

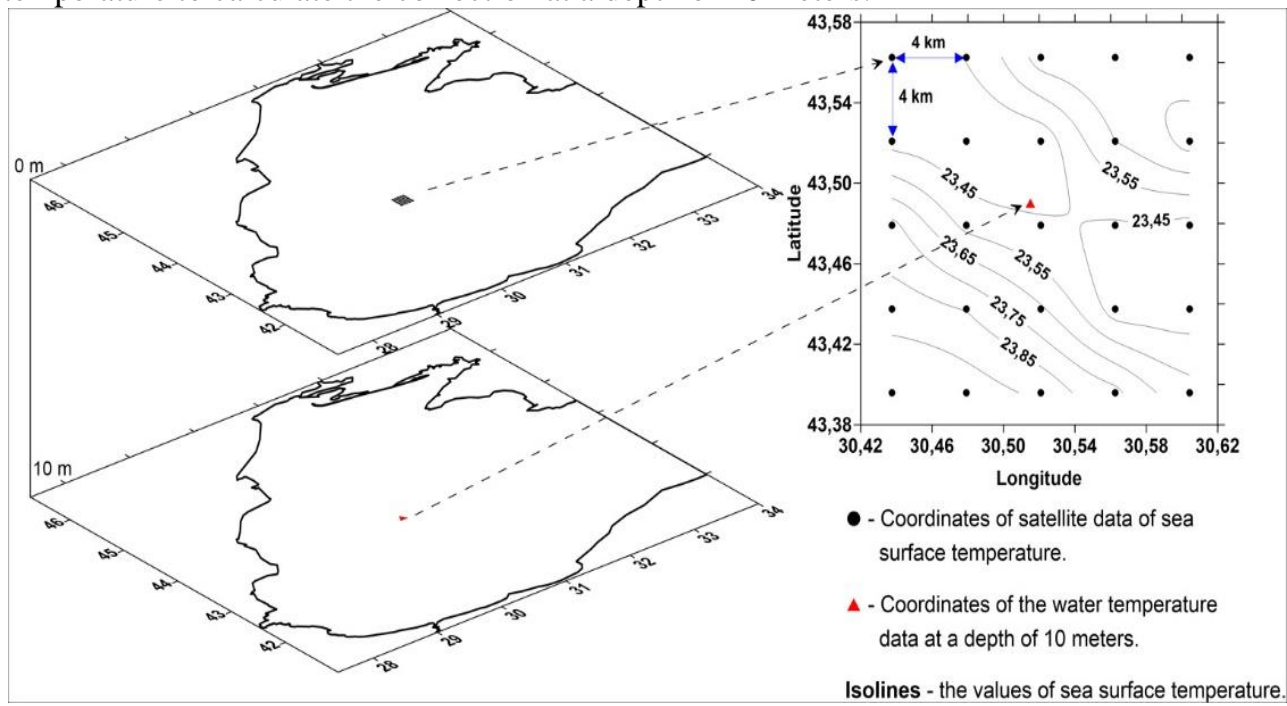

Fig. 3. Diagram of the location of satellite data of sea surface temperature to calculate the correction at a depth of 10 meters.

The fields of water temperature have been decomposed into the ranks on the Chebyshev polynomials and the decomposition coefficients

( $A_{00}, A_{10}, A_{20}, A_{30}, A_{01}, A_{02}, A_{11}, A_{12}, A_{13}$ ) were calculated according to the equation (5).

Depending on the task the number of coefficients in the multiple regression equation may be different. In our case for a more accurate assessment of the relationship between the sea surface temperature and the temperature at a depth of 10 meters 5 coefficients of decomposition ( $A_{00}, A_{20}, A_{01}, A_{02}, A_{12}$ ) have been applied. Also, in the multiple regression equation another coefficient was added. That coefficient was the value of the water temperature at a depth of 20 meters.

Using a simplified method of calculation, the equation (9) will be written as

$$
\delta y_{10}=0.378 x_{20}+0.755 A_{00}+2.822 A_{20}+0.513 A_{01}-1.913 A_{02}+1.911 A_{12}-1.875,
$$


where $\delta y_{10}$ - the water temperature at depth 10 meters; $x_{20}$ - the water temperature at a depth of 20 meters; $A_{00}, A_{20}, A_{01}, A_{02}, A_{12}$ - coefficients of decomposition of the sea surface temperature field.

The results of the studies show a high correlation between values of water temperature at a depth of 10 meters, the water temperature at a depth of 20 meters and coefficients of decomposition $A_{00}, A_{20}, A_{01}, A_{02}, A_{12}$ in spring - autumn period. The multiple correlation coefficient $(R)$ was 0.90 and greater than the critical value $R(0.05)=0.14$. Probabilistic error multiple correlation coefficient $\left(E_{R}\right)$ was 0.005 the ratio $\left(R / E_{R}\right)$ was 180 . This indicates the significance of $R$ and a reliable correlation. Standard error $(S)$ of correlation was $1.7^{\circ} \mathrm{C}$.

The calculated value $F=404$ and greater than the critical value $F_{0.05}=2.11$. The criterion $\left(S / \sigma_{T}\right)$ equal to 0.18 at $\mathrm{n}=605$ that does not exceed the tolerable error 0.67 $\left(S / \sigma_{T} \leq 0.67\right)$. This indicates about the significance of the regression equation, reliability and effectiveness of the method of calculation of correction by the equation (13).

Described above example of calculation of the vertical distribution of water temperature at three stations was used for the visualization.

The results taking into account the water temperature corrections calculated on the regression equations (Table 3) and equation (13) are presented in Fig. 4.

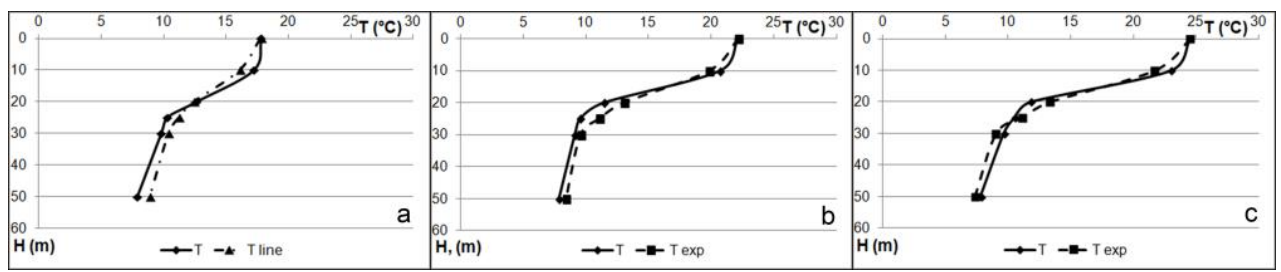

Fig. 4. The graphs of the vertical distribution of water temperature at stations 1 (a), 2 (b) and 3 (c) built on the PFL data $(T)$ and calculated values by the equations of exponential $\left(T_{\exp }\right)$ and linear $\left(T_{\text {line }}\right)$ regressions (Table 2), taking into account the corrections to the water temperature.

Fig. 4 shows a significant increase in the accuracy of calculated water temperature values on standard levels compare to Fig. 2. Improvement of accuracy of calculations of vertical distribution of temperature of water is confirmed by values of standard errors $(S)$ presented in Table 4.

Table 4.

Standard errors $(S)$ of calculating the vertical distribution of water temperature considering the corrections in water temperature.

\begin{tabular}{|c|c|c|c|c|}
\hline $\begin{array}{c}\text { Number } \\
\text { station }\end{array}$ & $\begin{array}{c}\text { Number } \\
\text { square }\end{array}$ & Month & $\begin{array}{c}\text { The regression } \\
\text { equation }\end{array}$ & S \\
\hline 1 & 44 & 5 & $y=0.9207 x-0.6741$ & 0.93 \\
\hline 2 & 51 & 6 & $y=4.6081 e^{0.0628 x}$ & 1.23 \\
\hline 3 & 26 & 9 & $y=5.1155 e^{0.0531 x}$ & 1.12 \\
\hline
\end{tabular}

The results of calculations of the vertical distribution of water temperature by satellite data on 160 stations in the Black Sea in period of spring-autumn in 2017 year showed that the standard error $(S)$ amounted to $2^{\circ} \mathrm{C}$, at $\mathrm{n}=960\left(\sigma_{\mathrm{T}}=6.4\right)$. 


\subsection{Calculation of the vertical distribution of water temperature in the Black Sea by satellite data}

The local calculation of the vertical distribution of water temperature in the Black Sea by satellite data in the layer $0-50$ meters at several stations can be easily carried out by applying the above equations. But if the whole water area of the Black Sea should be counted, this process is very time consuming.

Therefore, we designed a prototype of a computer program (hereinafter referred to as the Program) for the calculating of the vertical distribution of water temperature in the Black Sea by satellite data. The Program includes 864 exponential and linear regressions equations to calculate the vertical distribution of water temperature on all squares (Fig. 1) in the Black Sea and the months between May - October; linear regression equations to calculate corrections for temperature at standard levels (10, 20, 25, 50 meters); intervals to determine the calculation by exponential or linear regression equations.

Thus, the Program automatically determines where and by what equations the vertical distribution of water temperature in the Black Sea and the corrections to the water temperature can be calculated.

The initial data for the calculations are only daily satellite data of the sea surface temperature and the month of the year.

To visualize the results of the calculations by the Program the maps of the spatial distribution of water temperature at standard levels, zonal (latitude $44^{\circ} \mathrm{N}$ ) and meridional (longitude $36^{\circ} \mathrm{E}$ ) cuts for 30.05.2017, 27.06.2017 and 10.09.2017 were built.

The spatial distribution of sea surface temperature on satellite data shown in Fig. 5.

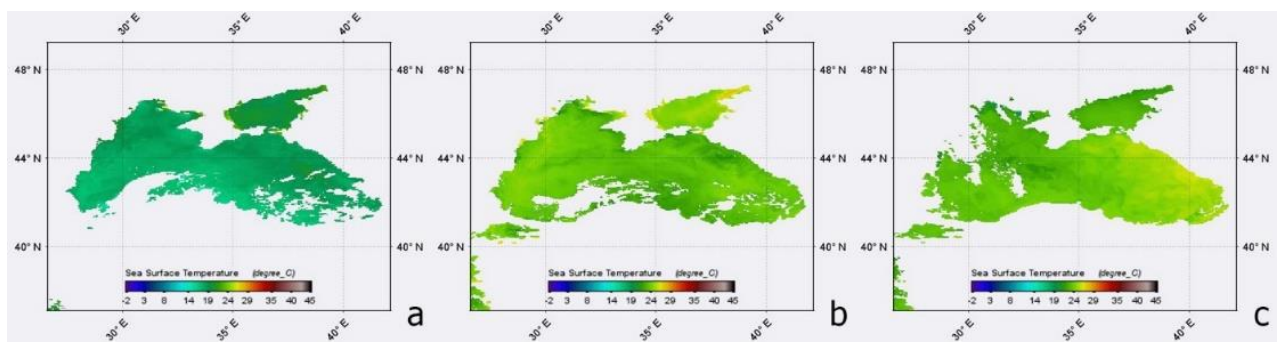

Fig. 5. The spatial distribution of Black Sea surface temperature on satellite data for 30.05.2017 (a), 27.06.2017 (b) and 10.09.2017 (c).

Maps of spatial distribution of the surface temperature of the Black Sea on satellite data (Fig. 5) were built with the help of specialized software NASA - SeaDAS (NASA's SeaDAS, 2019).

The missing satellite data can be seen in Fig. 5 as a white area. The reason of this might be a high cloud cover at the time of measurement. Temperature scale corresponds to the original scale for these measurements (NASA's OceanColor Web, 2019).

The results of calculations of the vertical distribution of water temperature on satellite data at the standard levels in the Black Sea for 30.05.2017 are shown in Fig. 6.

The results of calculations of zonal (latitude $44^{\circ} \mathrm{N}$ ) and meridional (longitude $36^{\circ} \mathrm{E}$ ) cuts in the Black Sea for 27.06.2017 and 10.09.2017 are presented in Fig. 7 respectively. 
Figs. 6 and 7 are built using computer program Ocean Data View (ODV) that is intended for the interactive exploration and graphical display of oceanographic and other geo-referenced profile, trajectory or time - series data (Schlitzer, 2019).

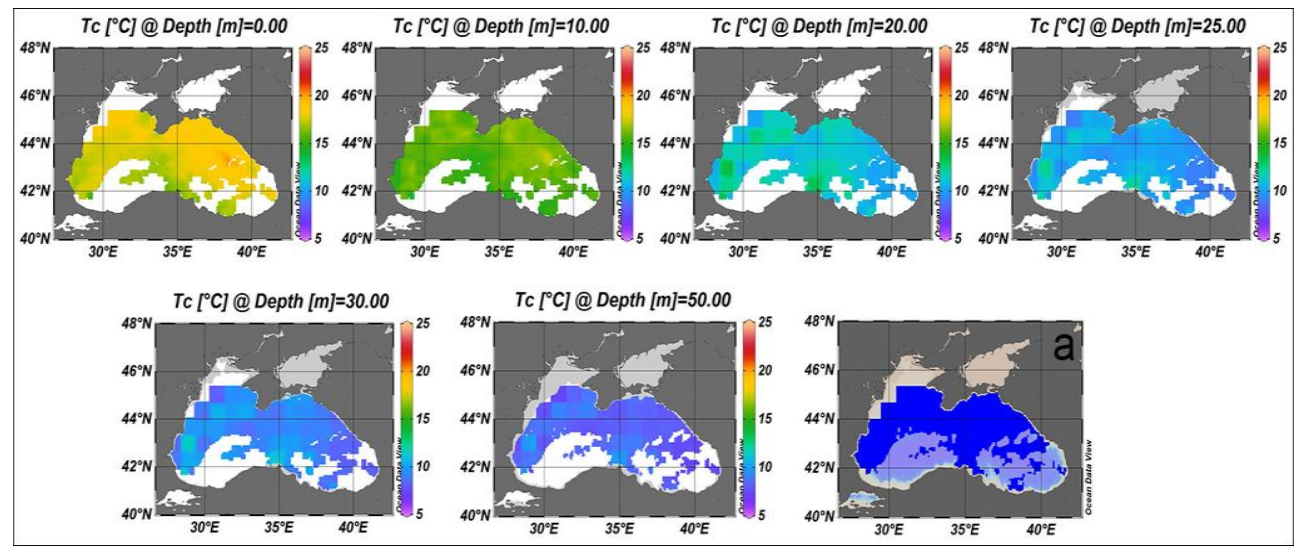

Fig. 6. Maps of spatial distribution of calculated water temperature $\left(T_{\mathrm{c}}\right)$ at the standard levels in the Black Sea for 30.05.2017. Map (a) is map of the distribution of data for calculation.

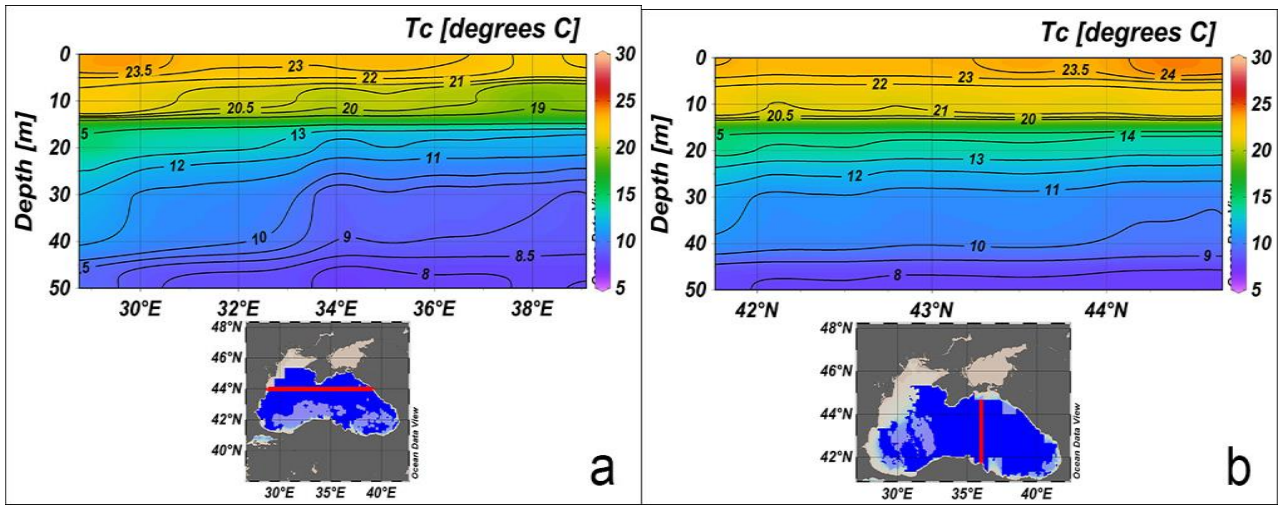

Fig. 7. Distribution of calculated of water temperature $\left(\mathrm{T}_{\mathrm{c}}\right)$ on zonal at latitude $44^{\circ} \mathrm{N}$ (a) and meridional at longitude $36^{\circ} \mathrm{E}$ (b) cuts in the Black Sea for 27.06.2017 and 10.09.2017, respectively. The maps show the location of cuts in the Black Sea.

\section{CONCLUSIONS}

Research results from the calculations of the vertical distribution of water temperature in the Black Sea by satellite data at standard levels $(0,10,20,25,30,50$ meters) in spring autumn period showed that the change in the vertical profile of water temperature obeys the exponential law of distribution. 
The linear law of distribution is dominated when the deviation of sea surface temperatures $\left(T_{0}\right)$ from climatic water temperature values $\left(T_{\text {clim }}\right)$ is more than $\pm 2{ }^{\circ} \mathrm{C}$.

Water temperature corrections are introduced on the levels of 10, 20, 25 meters during spring - summer, and in autumn - on the levels 10, 20, 25, 50 meters.

Standard error $(\mathrm{S})$ of calculations of the vertical distribution of water temperature in the Black Sea by satellite data in 2017 year is amounted to $2{ }^{\circ} \mathrm{C}$.

Designed by us, the prototype of a computer program to calculate the vertical distribution water temperature in the Black Sea by satellite data could serve as a basis for the establishment of a "Monitoring system of water temperature in the Black Sea". With the help of which the dynamics of water temperature and water temperature change effects on hydrobiological, hydrochemical, hydrophysical processes in the Black Sea and the ecosystem of the sea in general can be evaluated.

In our view the described algorithm of calculation of the vertical distribution of water temperature by satellite data can be applied to others water area of the World Ocean taking into account their hydrological conditions.

\section{R E F E R E N C E S}

Abuzyarov, Z. K., Kudryavaya, K. I., Seryakov, J. I., \& Skriptunova, L. I. (1988). Marine Forecasts. Leningrad, Gidrometeoizdat. (in Russian)

Ahn, H. (2018). Probability and Statistics for Science and Engineering with Examples in R, Second Editon. California, Cognella Inc. \& University Readers.

Andrianova, O.R., Batyrev, A.A., Skipa, M.I. \& Sriberko, A.V. (2004) Undersatellite authentication and interpretation of the data of space surveys of a sea surface. Kosmična Nauk. ì Tehnol. 10, 92-95. (in Russian; Abstract in English)

Andrianova, O.R., Skipa, M.I., Sryberko, A. V. \& Stepanova, Y. V. (2015) Estimation of ability of vertical temperature distribution's calculation for the Black sea's water by satellite data. Her. ONU 20, 9-21. (in Russian; Abstract in English)

Deep, R. (2006) Probability and Statistics: with Integrated Software Routines. Elsevier Academic Press Publications, USA.

Draper, N.R. \& Smith, H. (1998) Applied Regression Analysis. John Wiley \& Sons, Inc., Hoboken, NJ, USA.

Dufois, F., Penven, P., Peter Whittle, C. \& Veitch, J. (2012). On the warm nearshore bias in Pathfinder monthly SST products over Eastern Boundary Upwelling Systems. Ocean Model. 47, 113-118.

Eliseeva, I. I. (ed), Kurysheva, S. V., Kosteeva, T. V., Pantina, I. V., Mikhailov, B. A., Neradovskaya J.V., Shtroe, G. G., Bartels, K . \& Rybkina, L. R. (2007) Econometrics. Moscow, Finance and Statistics. (in Russian)

Gil, A., Segura, J. \& Temme, N.M. (2007) Numerical Methods for Special Functions. Philadelphia, Society for Industrial and Applied Mathematics.

Glagoleva, M.G. \& Skriptunova, L.I. (1979) Prediction of Water Temperature in Oceans. Leningrad, Gidrometeoizdat. (in Russian)

Hogg, Robert V., Tanis, Elliot A. \& Zimmerman, D. (2015) Probability and Statistical Inference. 9th ed., Pearson Education, Inc., USA. 
Kara, A.B., Barron, C.N., Wallcraft, A.J., Oguz, T. \& Casey, K.S., (2008) Advantages of fine resolution SSTs for small ocean basins: Evaluation in the Black Sea. J. Geophys. Res. 113, C08013.

Kobzar, A.I. (2006) Applied Mathematical Statistics. For Engineers and Scientists. Moscow, Fizmatlit. (in Russian)

Kudryavaya, K.I., Seryakov, E.I. \& Skriptunova, L.I., (1974) Marine hydrological forecasts. Leningrad, Gidrometeoizdat. (in Russian)

Manev, A., Palazov, K., Stoianov, St. \& Raykov, St. (2005) Satellite researches of temperature anomalies on the Black sea surface. Trakia J. Sci. 3, 24-27.

NASA's OceanColor Web (2019). - National Aeronautics and Space Administration, OceanColor Web. Available from: https://oceancolor.gsfc.nasa.gov/cgi/l3 [Accessed May 2019].

NASA's SeaDAS (2019). - National Aeronautics and Space Administration, SeaDAS. Available from: https://seadas.gsfc.nasa.gov/about/ [Accessed July 2019].

NOAA (2019). - National Oceanic and Atmospheric Administration, National Oceanographic Data Center, World Ocean Database. Available from: https://www.nodc.noaa.gov [Accessed May 2019].

Oguz, T., Tugrul, S., Kideys, A.E., Ediger, V. \& Kubilay, N. (2004) Physical and biogeochemical characteristics of the Black Sea (28, S). sea 14, 1331-1369.

Schlitzer, R., 2019. Ocean Data View. https://odv.awi.de

Shapiro, G.I., Aleynik, D.L. \& Mee, L.D. (2010) Long term trends in the sea surface temperature of the Black Sea. Ocean Sci. 6, 491-501. 